\title{
METODOLOGI PEMAHAMAN SYARI'AH (Analisis Muqaddimah Kitab al-Muwafaqat Karya Asy-Syatibi)
}

\author{
Oleh: Mukhlis Abidin \\ Nihaie20@yahoo.com
}

\begin{abstract}
Legality is one basic of penal law beside culpability in deciding the punishment. Legality is often perceived similar to law enforcement. According to Article 1 (1) of the Penal Law (KUHP), the law refers to written law. In fact, there is also living law mentioned in the Constitution. This kind of situation often causes the judge decision fails to meet social justice since the decision is merely based on formal law and neglected material law, such as in the case of Minah in Banyumas Court. Thus, progressive approach is necessitated in order to understand legality both in formal and material law in accordance with national legal ideals, Pancasila.
\end{abstract}

Keywords: legality, law, living law, legal ideals

\begin{abstract}
Abstrak
Al-Muwafaqat, merupakan karya ilmiah dalam bidang ushul fiqh sekaligus salah satu bentuk reformasi ilmiah secara menyeluruh. Buku ini, bukan hanya menjelaskan dasar- dasar ilmu ushul fiqh dengan metodologi baru yang berlandaskan penelitian penuh (istiqra') dari sumber utama Syariah (Al Qur'an dan Sunnah), tapi juga menjelaskan dasar-dasar utama untuk memahami Syariah secara menyeluruh.

Syari'ah yang diturunkan kepada umat manusia bertujuan untuk mengatur kehidupan manusia supaya lebih baik. Syari'ah diturunkan ke dunia ini agar terjaga agama, jiwa, akal, keturunan, dan harta manusia, yang kesemuanya itu merupakan unsur utama kehidupan manusia. Kelima unsur penting tersebut disebut "Dhoruriyat Khomsah". Syari'ah juga diturunkan untuk memperhatikan kebutuhan-kebutuhan manusia yang kalau tidak disediakan, maka manusia akan hidup dalam keadaan susah dan payah, yang terkenal kemudian dengan "Hajiyat" begitu juga diturunkan untuk memperhatikan "Tahsinat" yang menganjurkan makarimul akhlak dan perbuatan baik.
\end{abstract}




\section{A. Pendahuluan}

Kitab Al-Muwafaqat, karya terbesar Imam Syatibi, merupakan karya ilmiah dalam bidang ushul fiqh sekaligus salah satu bentuk reformasi ilmiah secara menyeluruh. Buku ini, bukan hanya menjelaskan dasar- dasar ilmu ushul fiqh dengan metodologi baru yang berlandaskan penelitian penuh (istigra') dari sumber utama Syariah (Al Qur'an dan Sunnah), tapi juga menjelaskan dasar-dasar utama untuk memahami Syariah secara menyeluruh.

Al Qur'an yang merupakan pedoman utama umat Islam berisikan pokok-pokok ajaran Islam secara global, kemudian dijelaskan oleh As-Sunnah. Yang keduanya menggunakan bahasa Arab. Oleh karenanya, bagi siapa saja yang ingin memahami kedua kitab tersebut, harus memahami pula bahasa Arab.

Syari'ah yang diturunkan kepada umat manusia bertujuan untuk mengatur kehidupan manusia supaya lebih baik. Syari'ah diturunkan ke dunia ini agar terjaga agama, jiwa, akal, keturunan, dan harta manusia, yang kesemuanya itu merupakan unsur utama kehidupan manusia,. Tanpanya barangkali manusia akan punah. Kelima unsur penting tersebut disebut "Dhoruriyat Khomsah". Syari'ah juga diturunkan untuk memperhatikan kebutuhan-kebutuhan manusia yang jika tidak disediakan, maka manusia akan hidup dalam keadaan susah dan payah, yang terkenal kemudian dengan "Hajiyat" begitu juga diturunkan untuk memperhatikan "Tahsinat" yang menganjurkan makarimul akhlak dan perbuatan baik.

Seluruh pembahasan fiqih, bahkan pembahasan syari'ah secara keseluruhan tidak akan bisa dilepaskan dari tiga permasalahan di atas. Oleh karenanya, setiap orang Islam diharapkan mampu meletakkan tiga tujuan utama kehidupan itu pada proporsinya masing-masing. Yakni memprioritaskan masalah yang paling penting kemudian yang penting dan kurang penting dan seterusnya. Salah di dalam meletakkan unsur-unsur tadi, merupakan sebuah kegagalan di dalam memahami syari'ah, sekaligus kegagalan di dalam bertindak.

Oleh karenanya, jika seseorang hendak mengetahui semua hal itu secara sempurna, tidaklah cukup hanya mengetahui dalil-dalil syari'ah secara sepihak dan sepenggal, akan tetapi dia harus memahami dalil-dalil syari'ah tersebut 
secara menyeluruh dan menjadikan dalil-dalil tersebut satu kesatuan yang tidak dapat dipisah-pisahkan. Allah sendiri telah memberikan isyarat dan pesan seperti ini di dalam salah satu firman-Nya :

عَدُوٌ مُبينُ

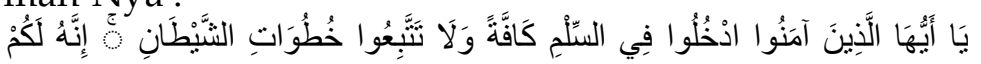

"Wahai orang-orang yang beriman masuklah kedalam Islam secara keseluruhan" (QS.Al Baqarah : 208)

Ini juga dikuatkan dalam ayat lain :

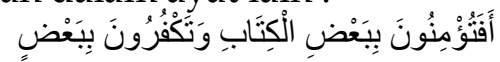

"Apakah engkau beriman kepada sebagian isi kitab dan mengkafiri sebagian yang lain?" (QS. Al Baqarah: 85)

Dari keterangan di atas, bisa dikonklusikan bahwa untuk memahami Syari'ah Islam ini dibutuhkan dua perangkat yang sangat urgen, yaitu pengetahuan tentang bahasa Arab dan pengetahuan tentang tujuan diturunkannya syari'ah dan penempatan segalanya menurut prioritas yang dikehendaki syari'ah.

Masalahnya, banyak ulama yang telah memperhatikan dan membahasnya, baik itu dalam bentuk kaidah-kaidah bahasa Arab, dalam ilmu Nahwu dan Shorof, maupun dalam bentuk yang lebih detail lagi di dalam ilmu ushul fiqh. Tetapi, sebagian besar ulama tidak banyak membahas secara lengkap dan sistematis masalah maqhosid ini, selama 3 abad lebih mereka tenggelam di dalam metodologi ushul fiqih yang telah diletakkan oleh para pendahulunya, sehingga datanglah Imam Syatibi pada abad ke 8, meletakkan batu pertama dalam masalah ini.

Memang -harus diakui- bahwa pembahasan maqhosid sendiri sebetulnya telah disentuh, walau sekilas, oleh sebagian ulama, seperti Imam Tirmidzi di dalam bukunya "As -Sholat wa Maqhoshiduha", Abu Manshur Al Maturudy di dalam "Ma'khod Syarai", Abu Bakar Qoffal As- Syasyi di dalam "Mahasin Syari'ah" , Al Baqilani di dalam "Ahkam wa 'ilal", Al Qhodhi Husain di dalam "Asror Fiqih" nya, Imam Haromain di dalam "Burhan", dan generasi sesudahnya seperti Imam Ghozali, Fakhruddin Ar Rozi, Saifuddin Al Amidi, Ibnu Hajib, Isnawi, dan Ibnu Subki (www.ahmadzain,com).

Selain ulama ushul di atas, terdapat ulama-ulama muhaqiqun yang sebenarnya lebih banyak perhatiannya 
kepada masalah maqhosid dari pada mereka, yang karya-karya mereka justru pada akhir-akhir ini dijadikan rujukan dan referensi utama oleh banyak ulama kontemporer di dalam banyak karyanya, mereka itu adalah : Izuddin Abdus Salam dengan bukunya "Qowaid Ahkam fi Masholih Al anam", dan muridnya Syihabuddin Al Qorrofi di dalam "Al furuq", begitu juga Ibnu Taimiyah di dalam "Majmu' Fatawa" dan muridnya Ibnu Qoyyim di dalam "I'lamul Muwaqi'in 'an Robbil Alamin" (www.ahmadzain,com).

Al-Muwafaqat adalah nama asli dari karya Imam Syatibi ini, tetapi beberapa ulama dan muhaqqiqin menambahkannya dengan "Muwafaqot fi Ushul Syari'ah" seperti yang ditulis Syekh Daraz, juga "Muwafaqot fi Ushul Ahkam" sebagaimana ditulis oleh Muhyidin Abdul Hamid (www.ahmadzain,com).

Disebut kitab Muwafaqat didasarkan pada mimpi وفقت به بين مذهبي ابن القاسم وأبي : beliau. Muwafaqat mempunyai arti حنيفة (penggabungan antara mazhab Ibn al-Qasim Malikiyah dan mazhab Abu Hanifah) (Syatibi, tt : 7).

\section{B. Profil Imam Syatibi}

Nama lengkap beliau adalah Abu Qasim bin Khalaf bin Ahmad asy-Syatibi al-Andalusi ad-Dharir. Kelahiran beliau adalah pada akhir tahun 538 hijrah di Syatibah salah satu kampung di Andalusia.

Beliau dalam hal Hafaz Quran dan talaqqi Qiraat berguru pada Abi Abdullah Muhammad bin Abi al-'Asy. Kemudian ke Balinsiah sebuah kampung yang berhampiran dengan kampung beliau untuk membentangkan Kitab Taisir bagi Abi Amru ad-Daani. Beliau mengambil kitab ulama' Nahu daripada Abi Abdillah Muhammad bin Hamid

Kelebihan Imam Syatibi adalah imam yang diperakui hujahnya dalam bidang ulum Quran, Hadith dan bahasa, Tinggi kesabarannya, tenang dan khusyu'. Ketika ditanya tentang keadaan beliau, beliau tidak akan menambah tetapi hanya berkata al-'afiah. Beliau wafat pada 28 Jamadilakhir 509 hijrah. Dikebumikan di perkuburan Qadhi al-Fadhil Safhil Jabal al-Maqtam di Kaherah (www.ahmadzain,com). 


\section{Isi Kitab Muwafaqat}

Adapun Kitab al-Muwafaqot sendiri terdiri dari 4 juz dan dijadikan 2 jilid yang isinya dibagi menjadi 5 bagian. Lima bagian tersebuta adalah : Muqaddimah (Premis-premis), Kitab tentang Ahkam, Kitab tentang Maqhosid, Kitab tentang Dalil dan Kitab tentang Ijtihad.

\section{Pembahasan tentang Muqaddimah (Premis-premis).}

Muqaddimah (premis-premis) ini terdiri dari 13 Muqaddimah dan 5 pasal yang berisikan tentang pembahasan dasar-dasar ilmu ushul fiqh, sebagai pengantar menuju substansi yang sebenarnya. Adapun 13 Muqaddimah tersebut adalah :

\section{Muqaddimah ke-1}

Ushul fiqih dalam agama itu qoth'i, tidak dhonni. Alasannya, karena ushul fiqh itu berdasarkan prinsip umum syari'at yang bersifat qoth'i (yaitu : Dhoruriyat, Hajiyat dan Tahsinat) (Syatibi, tt : 10).

Penjelasan Muqaddimah pertama ini adalah :

Pertama, Sudah jelas bahwa prinsip umum syari'at itu bersifat pasti dengan istigra' (penelitian) yang memberikan faedah qath'i.

Kedua, - Ushul fiqh itu adakalanya berdasarkan dalil aqli yang qath'i dan berdasarkan pada penelitian menyeluruh terhadap dalil syar'i yang qath'i.

- Kalau ushul fiqh itu dhanni, maka tidak bisa dikembalikan kepada dalil aqli, karena sesuatu yang dhanni tidak bisa diterima oleh akal dan oleh universalitas syara'.

Ketiga, Kalau seandainya sesuatu yang dhanni itu dapat dijadikan dasar ushul fiqh, maka dapat juga dijadikan dasar agama, tetapi tidak demikian menurut kesepakatan umat Islam. Sehingga sesuatu yang dhanni itu tidak dapat dijadikan dasar ushul fiqh.

Ushul berarti dalil-dalil, dan dalil adalah yang menunjukkan sesuatu yang pasti (qath'i). Sedangkan sesuatu yang bersifat qath'i adalah prinsip umum syari'at. Jadi, maksud al-mahfudz dalam ayat al Qur'an adalah prinsip-prinsip umum, 
juga dalam firman Allah اليوم أكملت لكم دينكم yang dimaksudkan sudah sempurna adalah prinsip umumnya (Syatibi, tt : 12).

\section{Muqaddimah ke-2}

Muqaddimah-muqaddimah (premis-premis) dan dasar-dasarnya yang dipakai di dalam ilmu ini semuanya adalah qath'i, karena jika dhanni tidak memberikan kekuatan qath'i (pasti). Yang qath'i baik berupa hukum aqli (wajib, muhal dan jaiz), hukum adat (wajib, muhal dan jaiz), maupun sama'i (hasil pendengaran) berupa hadis mutawatir lafdzi yang qath'i ad-dalalah maupun mutawatir lafdzi (tetapi dengan penelitian lebih dahulu) (Syatibi, tt : 13).

\section{Muqaddimah ke-3}

Dalil-dalil aqli apabila digunakan di dalam ilmu Ushul fiqh ini tidak berdiri sendiri, tetapi digabungkan dengan dalil naqli, ditentukan pada jalur naqli atau dijelaskan sesuai dengan tujuan dalil naqli. Karena obyek ilmu ini adalah sesuatu yang bersifat syar'i, sedangkan akal bukanlah syari' (Syatibi, tt : 13).

Sedangan yang dimaksud dalil-dalil yang mu'tabar adalah dalil yang terangkum dari dalil-dalil dhanni yang mempunyai satu arti sehingga memberikan faedah qath'i. Oleh karena itu, arti yang disepakati secara mutawatir berkekuatan qath'i. Misalnya tentang kewajiban sholat, zakat menjadi qath'i karena secara mutawatir umat Islam mengatakan demikian, bukan hanya didasarkan pada firman Allah أقيموا الصلاة (Syatibi, tt : 14).

Demikian juga, Ijma' menjadi qath'i karena didasarkan pada pendapat beberapa orang yang kalau hanya pendapat perorangan bersifat dhanni dan lemah. Qiyas juga menjadi qath'i karena diambil dari dalil-dalil yang secara mutawatir memberikan faedah qath'i (Syatibi, $\mathrm{tt}:$ 14).

Umat Islam bahkan umat agama lain sepakat bahwa Syari'ah yang diturunkan kepada umat manusia bertujuan untuk mengatur kehidupan manusia supaya lebih baik. Syari'ah diturunkan ke dunia ini agar terjaga 
agama, jiwa, akal, keturunan, dan harta manusia, yang kesemuanya itu merupakan unsur utama kehidupan manusia,. Tanpanya barangkali manusia akan punah. Kelima unsur penting tersebut disebut " Dhoruriyat Khomsah ". Syari'ah juga diturunkan untuk memperhatikan kebutuhan-kebutuhan manusia yang jika tidak disediakan, maka manusia akan hidup dalam keadaan susah dan payah, yang terkenal kemudian dengan "Hajiyat" begitu juga diturunkan untuk memperhatikan "Tahsinat" yang menganjurkan makarimul akhlak dan perbuatan baik (Syatibi, tt : 15-16).

Dari kaidah ketiga ini dikembangkan satu pasal, yaitu Setiap dasar syari'ah yang belum ada nash akan tetapi sesuai dengan ruh syari'ah, maka dasar tersebut itu boleh dipakai. Karena akan menjadi qath'i dengan didukung banyak dalil. Seperti pendapat Imam Malik dan Syafi'i yang mengakui hadis Mursal sebagai dalil (Syatibi, tt : 16).

\section{Muqaddimah ke-4}

Semua permasalahan yang diletakkan di dalam ushul fiqih, tetapi tidak bisa dijadikan dasar untuk menjabarkan fiqih (masalah furu') atau adab-adab syarr'i, maka peletakkannya dalam ushul fiqh adalah hanya membuang energi dan tidak banyak manfaatnya. Misalnya perdebatan masalah mubah apakah taklif atau tidak, masalah al Qur'an dan lainnya (Syatibi, tt : 18).

Dari kaidah keempat ini dikembangkan satu pasal yaitu Setiap masalah Ushul Fiqh yang menjadi dasar fiqh yang menyebabkan perbedaan dalam hal furu'iyah, maka penjelasan dalil bagi golongan yang berbeda pendapatnya itu tidak berguna. Misalnya perdebatan tentang taklif bagi orang kafir dan lainnya (Syatibi, tt : 19).

\section{Muqaddimah ke-5}

Menyibukkan diri di dalam banyak teori ilmu tanpa ada kaitannya dengan amal perbuatan (perbuatan hati dan anggota badan) berarti menyibukkan diri dalam hal yang tidak dianggap baik oleh dalil syar'i. 
Hal ini diajarkan oleh al-Qur'an. Misalnya ketika alQur'an menjawab pertanyaan tentang ahillah. Al-Qur'an menjawabnya dengan kalimat قلى مو اقيت للناس و الحج yakni menjawab pertanyaan dengan dihubungkan dengan perbuatan manusia (haji) bukan semata-mata menjawab

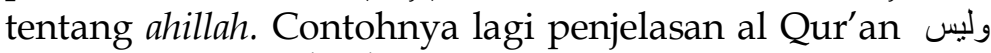
kata birr dalam ayat tersebut mempunyai arti taqwa bukan pengetahuan tentang cara masuk rumah (Syatibi, tt : 20).

Namun, apabila sesuatu yang bukan terkait dengan tuntutan itu menjadi sandaran tuntutan, maka berarti

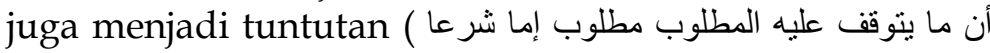
(و إما عقلا (Seperti ilmu bahasa, Nahwu, Tafsir dan lainnya (Syatibi, tt : 27).

\section{Muqaddimah ke-6}

Pengetahuan tentang sesuatu yang dituntut, terkadang mempunyai arti yang sesuai dengan pemahaman pada umumnya (mudah difahami) dan terkadang berbeda dengan pemahaman pada umumnya (sulit difahami).

Contoh pemahaman yang pertama adalah mengartikan bintang dengan benda yang terlihat malam hari, dan contoh pemahaman yang kedua adalah bintang diartikan dengan benda langit yang bercahaya dan seterusnya (Syatibi, tt : 28).

\section{Kaidah ke-7}

Tuntutan Syari' terkait dengan ilmu syar'i adalah bertujuan untuk menjadi sarana ibadah kepada Allah bukan untuk tujuan lain. Dalilnya adalah :

a. Setiap ilmu yang tidak membuahkan perbuatan, tidak dianggap baik oleh syara'.

b. Syara' menjelaskan bahwa tujuan pengutusan para nabi adalah untuk ibadah kepada Allah. Misalnya

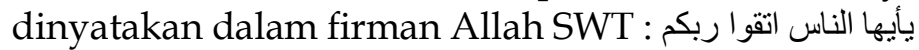

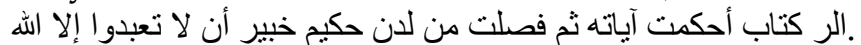

c. Banyak dalil yang menyatakan bahwa ruh ilmu adalah amal, karena jika tidak demikian, ilmu tidak dapat 
dimanfaatkan. Hal ini dinyatakan dalam firman Allah إنما يخشى الله من عباده العلماء (Syatibi, tt : 31).

Dalam kaidah ketujuh ini ada satu pasal, yaitu hanya orang bodoh yang mengingkari keutamaan ilmu. Pasal ini mempunyai dua arti, arti pokok dan arti tabi'. Arti pokoknya adalah bahwa keutamaan ilmu telah diakui oleh syara' di atas keutamaan syahid, karena dapat mengantarkan pada amal. Arti kedua adalah bahwa pemilik ilmu itu mulia meskipun kenyataannya tidak mulia, sebaliknya orang bodoh itu hina meskipun kenyataannya mulia (Syatibi, tt : 35).

\section{Kaidah ke-8}

Ilmu yang mu'tabar menurut syara' (yang dipuji oleh Allah dan Rasul) adalah ilmu yang berbuah amal perbuatan, sehingga pelakunya tidak terpengaruh oleh hawa nafsunya (Syatibi, tt : 36 ).

Tingkatan ilmu ada tiga macam, yaitu :

a. Orang yang mencari ilmu, tetapi tidak mencapai kesempurnaan. Mereka ini dalam tingkatan taqlid.

b. Orang yang mencari ilmu dengan cara mencari dalildalil, sehingga ia lebih tinggi daripada tingkatan taqlid.

c. Orang yang ilmunya telah menjadi sifat yang menetap mendalam, sehingga ilmunya tidak bercampur dengan hawa nafsunya, inilah orang yang rasikh ilmunya. Orang dalam tingkatan inilah yang berhak menterjemahkan syari'ah, dalilnya antara lain firman Allah أمن هو قآنت آنآء الليل ساجدا وقائما يحذر الآخرة ويرجو (36) رحة (Syatibi, tt : 36-38).

Dari penjelasan ayat-ayat al Qur'an dapat disimpulkan bahwa orang yang berilmu adalah orang yang beramal. Ilmu yang mu'tabar adalah ilmu yang mengarah pada amal (Syatibi, tt : 39).

Dalam kaidah kedelapan ini ada satu pasal, yaitu tingkatan ilmu itu sesuatu yang bersifat batin.

Sebagaimana yang digambarkan oleh Ibn Mas'ud di

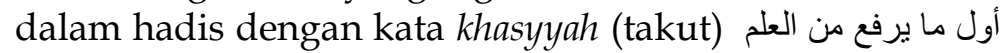
انما يخشي الله من : الخشوع : sebagai penjelasan ayat al-Qur'an عباده العلماء (Syatibi, tt : 42). 


\section{Kaidah ke-9}

Ilmu terdiri dari ilmu pokok (primer), ilmu pelengkap (sekunder) dan ilmu yang keduanya. Penjelasannya;

a. Ilmu Pokok (primer) adalah ilmu dasar, mu'tamad, obyek pencarian orang-orang yang rasikh ilmunya dan bersifat qath'i atau berdasar pada dasar yang qath'i. Syari'at Islam juga diturunkan dalam bentuk ilmu ini. Sehingga prinsip dan bahasannya (ushul dan furu') dijaga oleh Allah, sebagaimana firman Allah : إنا "Sesungguhnya kami menurunkan az-Zikr dan Kami-lah yang menjaganya". Hifd di sini bermakna menjaga maqasid yang menjadi sarana kebaikan dunia akhirat, yaitu dlaruriyat, hajiyat dan tahsiniyat (Syatibi, tt : 44).

b. Ilmu Pelengkap (sekunder) adalah ilmu yang berbilangan pemahamannya dan tidak qath'i, serta tidak berdasar pada dasar yang qath'i tetapi hanya pada dasar dhanni. Atau berdasar pada dalil qath'i tetapi berbilang pemahamannya (Syatibi, $\mathrm{tt}: 45$ ).

c. Ilmu yang bukan pokok dan bukan pelengkap, yang tidak berdasar pada dasar qath'i dan dhanni. Ilmu ini batal dan bukan termasuk ilmu yang mu'tabar. Misalnya ilmu nujm (Syatibi, tt : 51).

Dari kaidah kesembilan ini ada satu pasal, yaitu terkadang ilmu bagian pertama bercampur dengan ilmu bagian kedua. Misalnya ketika ahli fiqh menjelaskan hukum dengan ilmu nahwu (Syatibi, tt : 52).

\section{Kaidah ke-10}

Apabila dalil naql dan dalil aql bertentangan dalam permasalahan syar'iyyah, maka dalil naql didahulukan daripada aql. Dalil naql sebagai matbu' dan dalil aql sebagai tabi'. Alasannya adalah :

a. Apabila akal dapat menggantikan posisi naql, maka tidak ada bedanya antara akal dan naql dan ini batal menurut syari'at. 
b. Sebagaimana dijelaskan di dalam ilmu ushul dan ilmu kalam, bahwa akal tidak bisa menentukan baik buruk. Karena, apabila akal dapat menentukan baik buruk, maka syara' tidak berguna.

c. Jika akal dapat menentukan baik buruk, maka akal dapat membatalkan syari'at. Semuanya adalah tidak benar (Syatibi, tt : 53).

\section{Kaidah ke-11}

Jika Ilmu yang mu'tabar menurut syara' adalah ilmu yang berbuah amal perbuatan, maka ia terbatas pada yang ditunjukkan oleh dalil syar'i (Syatibi, tt : 56).

\section{Kaidah ke-12}

Metode ilmiah yang paling bermanfaat mengantarkan kepada sesuatu yang tahqiq adalah mengambil ilmu dari muhaqqiq secara sempurna (Syatibi, $\mathrm{tt}: 56)$.

Dari kaidah kedua belas ini ada dua pasal, yaitu;

a. Orang 'alim yang muhaqqiq itu mempunyai tandatanda yaitu :

1) Selalu mengamalkan ilmunya.

2) Ilmunya dipelajari dari para guru sebagaimana dilakukan oleh salaf al-sholih.

3) Mengikuti perilaku dan adab guru.

b. Karena ilmu harus dipelajari dari guru, maka caranya ada dua macam, yaitu :

1) Musyafahah. Inilah cara terbaik, karena murid dapat menyaksikan langsung sang guru.

2) Menelaah kitab-kitab para ulama, dengan dua syarat, pertama, dapat memahami isi kitab tersebut dan kedua, penulis kitab tersebut adalah orang yang ahli dalam bidang tertentu (Syatibi, tt : 56-61).

\section{Kaidah ke-13}

Setiap dasar ilmiah yang menjadi dasar amal, ilmu dan amal itu berlaku sesuai dengan kebiasaan yang memenuhi syarat dan rukun. Artinya bahwa ilmu yang dituntut itu menetapkan hukum dengan mengasumsikan adanya suatu perbuatan. Apabila terjadi suatu perbuatan 
yang sesuai dengan ilmu itu, maka itulah hakikat ilmu. والوالدات يرضعن أولادهن حولين كاملين : Misalnya firman Allah adalah penetapan syara' yang sesuai dengan kenyataan (Syatibi, tt : 63).

\section{E. Pembahasan tentang Kitab Maqhosid}

Di dalam kitab ini dijelaskan secara terperinci bahwa Syari'ah Islam ini diturunkan kepada manusia semata-mata untuk kesejahteraan mereka. Karena berisikan kaidah-kaidah umum tentang kehidupan manusia, peraturan dan batas-batas yang semua manusia wajib mentaatinya dan melaksanakannya agar kehidupan mereka teratur, tertib dan aman. Sekilas nampaknya ajaran- ajaran di dalam agama Islam memberatkan dan mengikat kebebasan manusia. Tapi sebenarnya yang konsisten dengan ajarannya justru orang yang paling bebas dan paling tenang, karena seluruh ajarannya baik yang kecil maupun yang besar mengandung maslahah bagi manusia itu sendiri, walau dia tidak menyadarinya. Sebaliknya, yang keluar dan tidak mentaati aturan-aturan di dalamnya, akan terikat dan terbeleggu dengan nafsunya, yang walau kelihatannya enak dan menyenangkan tetapi pada hakekatnya adalah kerugian dan madhorot.

Orang yang paling mengetahui maslahat dan mafasid pada suatu kasus adalah para ulama yang telah menguasai ilmu syari'ah dan mengetahui hikmah di balik hukum yang terkandung di dalam ajaran Islam. Di antaranya :

1. Bahwa untuk menjaga syari'at ini secara keseluruhan, unsur-unsur di dalamnya harus dijaga walau sekecil apapun. Karena kuliyat dan juz'iyat di dalam ajaran Islam merupakan satu kesatuan yang tidak bisa dipisahkan.

2. Begitu juga bahwa Syari'at Islam diturunkan dalam bahasa Arab .

3. Sengaja dipilih bahasa Arab, karena hanya bahasa Arab saja yang mempunyai "ma'na tab'i" (makna tersirat) yang paling mendetail di dalam susunan kata-katanya yang tidak dimiliki bahasa-bahasa lainnya. Oleh karenanya, tidak dibolehkan, bahkan tidak akan bisa menerjemahkan Alquran secara letterligh ke dalam bahasa lain. Yang bisa (dan dibolehkan) hanyalah menafsirkan kandungan $\mathrm{Al}$ quran secara global. 
4. Alquran - walaupun berbahasa Arab- akan tetapi diturunkan kepada umat umiyyin (yang tidak pandai membaca dan menulis), oleh karenanya hendaknya cara memahami Al Quran harus disesuaikan dengan pemahaman mereka. Maksudnya tidak bertele-tele di dalam membahas sebuah lafadh, tapi cukup mengetahui maksud dari kalimat tersebut. Inilah rahasia kenapa $\mathrm{Al}$ Quran diturunkan dengan tujuh huruf. Oleh karena itu, Umar bin Khattab ketika ditanya tentang arti " $a b b a$ " dalam ayat (wafaakihata wa abba) beliau menjawab : kita tidak diperintahkan untuk bertele-tele seperti itu. Bahkan beliau menghukum seorang yang bernama Dhobii', karena selalu menanyakan makna walmursalaati dan wal ashifat.

5. Begitu juga di dalam memahami masalah aqidah, termasuk di dalamnya ayat-ayat sifat dan mutasyabihat, cukup dipahaminya secara umum tanpa tenggelam di dalam masalah-masalah yang pelik.

6. Dalam furu' yang berhubungan dengan ibadah amaliyah, Alquran meletakkan kaidah-kaidah yang bisa dipahami orang awam, seperti tanda untuk mengetahui datangnya waktu-waktu sholat, puasa dengan tenggelamnya matahari atau terbitnya bulan.

7. Syari'at Islam yang diturunkan kepada umat manusia ini mudah dilaksanakan oleh siapapun juga, karena tidak membebani seseorang kecuali menurut kadar kemampuannya.

8. Ajaran- ajarannya sangat indah, tidak ada yang perlu ditakutkan. Kalau ada beberapa hukuman yang dirasakan secara sekilas oleh sebagian orang sifatnya kejam dan tidak berperikemanusian, seperti hukum potong tangan dan hukum rajam, sebetulnya itu didasari rasa kasihan dan pandangan yang lebih jauh, yaitu maslahat yang lebih besar yang akan didapatinya jika hukuman-hukuman tersebut dilaksanakan. Sebagaimana seorang dokter yang memotong sebagian anggota tubuh pasien untuk menyelamatkan hidupnya.

9. Begitu juga Islam mengajak manusia untuk masuk ke dalam komunitasnya, mengikuti ajaran-ajarannya, meninggalkan hawa nafsunya agar tercapai kemaslahatan dunia dan akhirat. 
10. Karena kemaslahatan dunia ini tidak akan mungkin bisa ditegakkan kecuali dengan mengekang hawa nafsu, sebagaimana yang sudah disepakati oleh orang-orang yang berakal.

11. Oleh karenanya, mengikuti bisikan hawa nafsu merupakan sumber kerusakan dunia dan akhirat, dan apabila masuk ke dalam amalan ibadah, maka akan membawa mafsadah yang besar, sebagiamana orang yang menjadikannya sebagai sarana untuk mencapai hawa nafsunya.

\section{F. Pembahasan tentang Kitab Ijtihad}

Ijtihad ada dua macam, yaitu;

1. Ijtihad yang tidak akan mungkin putus sampai hari kiamat.

Bentuk ijtihad ini berkisar kepada "tahqiq al manat" yaitu mencari menentukan illat atau sifat yang telah disepakati pada suatu obyek, seperti kriteria adil, faqir, miskin, besar kecilnya nafakah yang wajib diberikan suami kepada istrinya. Ini semua tergantung pada perorangan dan kondisi masing-masing. Di sini ijtihad mutlak diperlukan bagi siapa saja yang ingin menentukan hukum pada masalah tersebut.

2. Ijtihad yang mungkin terhenti dan tertutup. Ini ada tiga macam :

a. "Tanqih al Manat", yaitu penyaringan suatu alasan hukum dengan cara meniadakan perbedaan satu dengan yang lainnya, seperti : meniadakan perbedaan antara budak laki-laki dan perempuan .

b. "Takhrij al Manat", yaitu menentukan alasan dari sebuah hukum, seperti menentukan alasan diharamkannya khomr, menentukan alasan larangan membentak orang tua, dan lain-lainnya.

c. "Tahqiq al Manat", yaitu menerapkan alasan tersebut pada masalah-masalah yang belum disebut hukumnya dalam Al Qur'an atau Hadis .

Yang berhak berijtihad adalah orang yang menguasai dua hal, yang pertama adalah "maqhosid syari'ah" adapun yang kedua adalah kemampuan berijtihad dengan syarat-syaratnya. 


\section{G. Simpulan.}

Imam Syatibi telah mempersembahkan kepada kita lewat kitabnya muwafaqat tentang metodologi pemahaman $\mathrm{Al}$ Quran dan Sunnah yang menyeluruh dan konperehensif.

Dijelaskan bahwa Syari'ah Islam ini diturunkan kepada manusia semata-mata untuk kesejahteraan mereka. Karena berisikan kaidah-kaidah umum tentang kehidupan manusia. Karena itu, kitab ini merupakan "al qoidah" untuk merubah cara berpikir kita yang sering menyibukkan diri dengan masalah parsial kepada cara berpikir secara kuliyyat (menyeluruh), dari perhatian kita yang begitu besar terhadap hal-hal yang sifatnya formalitas menuju perhatian kita kepada inti dan substansi, merubah keadaan kita yang telah terlalu tenggelam mengejar sarana menuju keadaan yang lebih baik, yaitu selalu mengedepankan tujuan, merubah kebiasaan dalam mempertahankan taqlid menuju generasi yang kreatif dan penuh inisiatif. 


\section{DAFTAR PUSTAKA}

Al-Ghazaly, Abu Hamid Muhammad ibn Muhammad, AlMustashfa fi 'Ilm al-Ushul. Beirut. : Dar al-Kutub al'Ilmiyah. $1417 \mathrm{H}$

Al-Syafi'i, Muhammad ibn Idris, Al-Umm. Beirut : Dar al-Fikr, t.t..

Al-Syatibi, Abi Ishaq Ibrahim Al-Lahmi, Al-Muwafaqat Fi Usul Al-Shari'at, Beirut : Dar Al-Ma'rifat, t.t..

--------, Al Muwafaqat fi Ushul al Ahkam, Beirut Dar al-Fikr, tt. -------, al I'tisham, Beirut: Dar Al-Ma'rifat, t.t.

Ibn Qudamah, 'Abdullah ibn Ahmad., Al-Mughny. Maktabah al-Riyadh al-Haditsah, t.t.

Isma'il, Sya'ban Muhammad, Ushul Figh al-Muyassar, Kairo : Dar al-Kitab al-Jami'iy, Cetakan pertama, $1415 \mathrm{H}$.

Khallaf, 'Abd al-Wahhab, $1401 \mathrm{H}$, Ilm Ushul al-Figh. Kuwait : Dar al-Qalam, Cetakan keempat belas.

Syaukany, Muhammad ibn 'Ali., Irsyad al-Fuhul ila Tahqiq al-Haq min 'Ilm al-Ushul, Beirut. : Dar al-Kutub al-'Ilmiyyah. Cetakan pertama, $1414 \mathrm{H}$.

www.ahmadzain,com 